\title{
VIABILIDADE DE SEMENTES DE TRIGO TRATADAS COM \\ FENITROTION E INFESTADAS POR SITOPHILUS ORYZAE (L.) \\ (COLEOPTERA: CURCULIONIDAE) DURANTE \\ O ARMAZENAMENTO ${ }^{(1)}$
}

\author{
ISABEL HELENA DE ALMEIDA ZEITUNI PLAZAS ${ }^{(3)}$, PRISCILA FRATIN MEDINA $^{(2)}$, \\ JOSÉ POLEZE SOARES NOVO ${ }^{(2)}$
}

\begin{abstract}
RESUMO
O esclarecimento de aspectos do comportamento de gorgulhos (Sitophilus spp.) em sementes de trigo armazenadas e o acompanhamento da qualidade física e fisiológica das sementes neste contexto, é essencial para aprimorar o monitoramento das sementes durante a armazenagem. Com o objetivo de avaliar a eficiência do inseticida fenitrotion, quanto à proteção oferecida às sementes de trigo contra os insetos Sitophilus oryzae (L.) (Coleoptera: Curculionidae) e de acompanhar a germinação das sementes tratadas ou não com inseticida, durante o armazenamento, sementes de trigo dos cultivares IAC-120 e IAC-350 foram tratadas ou não com fenitrotion três meses após a colheita e armazenadas em condições de ambiente de laboratório, em Campinas (SP), durante 15 meses. Em intervalos trimestrais, adultos de $S$. oryzae foram colocados nas amostras de sementes de cada uma das repetições dos tratamentos com insetos. Avaliou-se a sobrevivência desses insetos, bem como a progênie resultante. Em seguida, as sementes das amostras das repetições de todos os tratamentos com e sem insetos foram analisadas quanto ao grau de umidade, germinação e infestação por insetos. O inseticida fenitrotion, na dose recomendada pelo fabricante, não permitiu a proteção das sementes contra a infestação por $S$. oryzae, mesmo por períodos curtos de dois meses e que, na ausência de insetos, as sementes de trigo com elevado potencial de germinação inicial podem mantê-lo inalterado por períodos de 14 a 17 meses após a colheita, quando armazenadas em condições ambientes, em regiões com clima semelhante ao de Campinas.
\end{abstract}

Palavras-chave: Triticum aestivum, Sitophilus oryzae, sementes, armazenamento, germinação, controle químico.

\section{ABSTRACT \\ VIABILITY OF STORED WHEAT SEEDS WHEN TREATED WITH FENITROTHION AND INFESTED BY SITOPHILUS ORYZAE (L.) (COLEOPTERA: CURCULIONIDAE).}

Clarifying aspects of the weevils (Sitophilus spp.) behavior on stored wheat seeds, considering the seed quality, is essential to improve the seed management during storage. In order to evaluate the efficiency of the insecticide fenitrothion as protecting wheat seeds against Sitophilus oryzae (L.) (Coleoptera: Curculionidae) and to measure the seed germination during storage, wheat seeds of IAC-120 and IAC350 cultivars were treated or not with the insecticide fenitrothion three months after harvest and stored in laboratory ambient conditions, in Campinas, SP, Brazil, during 15 months. S. oryzae adults were trimonthly placed on seed samples from the replications of the treatments with insects. The survival of the insects was evaluated, as well as the resulting progeny. The insects were eliminated and seed moisture

( $\left.{ }^{1}\right)$ Parte da Dissertação de Mestrado apresentada pela primeira autora. Apresentado no XII Congresso Brasileiro de Sementes, Curitiba (PR), 2001, com apoio financeiro da FAPESP. Recebido para publicação em 17 de junho de 2002 e aceito em 13 de junho de 2003.

$\left(^{2}\right)$ Instituto Agronômico (IAC), Caixa Postal 28, 13001-970 Campinas (SP).

$\left({ }^{3}\right)$ Bolsista da FAPESP. 
content, germination and insect infestation were measured at the seed samples from the replications of all the treatments with or without insects. It was concluded that fenitrothion, in the recommended dose, does not protect wheat seeds, against S.oryzae infestation, even in short-term storage of two months. Wheat seeds with high initial germination level can keep their viability, for 14 to 17 months after harvest, when stored in ambient conditions, in regions, which have the climate similar to Campinas.

Key words: Triticum aestivum, Sitophilus oryzae, seeds, storage, germination, chemical control.

\section{INTRODUÇÃO}

O armazenamento é uma etapa crucial no programa de produção e abastecimento de sementes de trigo, pois como para a maioria das culturas propagadas por sementes, a época de colheita não coincide com a época mais adequada à semeadura. Por se tratar de uma cultura de inverno, o período de armazenamento (agosto/setembro a março/abril) no Estado de São Paulo coincide com umidades relativas e temperaturas elevadas, principalmente no verão.

Nesse contexto, a infestação por insetos se constitui em um dos piores problemas do armazenamento de sementes de trigo, sendo o gorgulho Sitophilus oryzae (L.) (Coleoptera: Curculionidae) considerado um dos principais insetos-praga do trigo armazenado (PuzzI, 1986), pois apresenta aparato bucal especializado em se alimentar de sementes inteiras e sadias. Além disso, oviposita dentro das sementes, onde suas larvas ápodes completam o desenvolvimento. A oviposição não ocorre em sementes trituradas ou em farinha e mesmo quando os ovos são postos, o desenvolvimento da larva é prejudicado (SINHA et al., 1988).

O desenvolvimento e o crescimento de $S$. oryzae são favorecidos em sementes com teores de água entre $12 \%$ e $15 \%$ e temperaturas entre 23 e 35 ${ }^{\circ} \mathrm{C}$ (SEDLACKe et al., 1991). Temperaturas mais baixas provocam grande redução nas taxas de desenvolvimento e crescimento deste inseto (GILBERT e RAWORTH 1996).

Há uma interação, porém, do teor de água das sementes e temperatura do ambiente, de modo que FRANK et al. (1992) observaram que o Sitophilus oryzae sobreviveu apenas nas sementes com teor de água de, no mínimo, $13,7 \%$, quando armazenadas a $20{ }^{\circ} \mathrm{C}$. Nas sementes com teor de água de $11,2 \%$, a progênie foi considerável apenas na temperatura de $35^{\circ} \mathrm{C}$ e no décimo mês de armazenamento. Além disso, a progênie desenvolvida nas sementes que apresentavam teor de água de $13,7 \%$ foi no mínimo 4 vezes maior do que nas sementes com teor de água de 12,1\%.

Nas sementes com teor de água de 13,7\%, armazenadas a 25,30 e $35^{\circ} \mathrm{C}$ a progênie atingiu os valores máximos após o sexto mês, variando entre 430 e 633 insetos nesses tratamentos, até o décimo mês.
A dureza do grão também pode influenciar fortemente a habilidade de $S$. oryzae em se reproduzir no trigo armazenado (McGaughey et al., 1990). Por isso, sementes de cultivares diferentes apresentam diversos níveis de resistência a insetos de armazenamento (SING e MATHEW, 1973; SING et al. 1975; McGaughey et al. 1990 e Cortez-Rocha et al. 1993).

Para proteger as sementes e os grãos armazenados, diversos inseticidas de contato têm sido empregados (HAREIN, 1982 e SNELSON, 1987). A eficiência do inseticida fenitrotion foi relatada na literatura por diversos autores, quanto a proteger sementes de trigo ou de arroz contra a infestação de $S$. oryzae, por períodos até de dois (PINTO et al., 1997), quatro (PAWAR e YADAV, 1985) ou seis meses (KAMEL e FAM, 1973) e segundo PAWAR e YADAV (1985), a degradação do inseticida é mais rápida nas sementes com teores de água de $12 \%$ e $14 \%$, do que naquelas com teor de água de $10 \%$.

Não há na literatura informações sobre o armazenamento de sementes de trigo tratadas com fenitrotion, por períodos mais longos. Essas informações são essenciais, quando se deseja guardar as sementes de uma safra para a outra, durante dezoito meses. O presente trabalho objetivou avaliar a eficiência do tratamento com o inseticida fenitrotion, na dose recomendada pelo fabricante, quanto à proteção oferecida às sementes de trigo armazenadas de uma safra para a outra em condições ambientes e verificar a conservação da capacidade de germinação das sementes de trigo dos cultivares estudados, tratadas ou não com inseticida, durante o armazenamento nessas condições.

\section{MATERIAL E MÉTODOS}

A presente pesquisa foi desenvolvida no Instituto Agronômico (IAC), em Campinas, (SP), durante 1999 a 2001. Empregaram-se sementes de trigo (Triticum aestivum) das cultivares IAC-120 (representando cultivares de sementes mais moles) e IAC-350 (representando cultivares de sementes mais duras), colhidas em setembro de 1999, beneficiadas em novembro e expurgadas com fosfina (fosfeto de alumínio), na dose de duas pastilhas de $3 \mathrm{~g}$ por $\mathrm{m}^{3}$, durante cinco 
dias, para eliminar todas as formas de insetos presentes. Em dezembro, as sementes foram homogeneizadas e divididas em 16 amostras de $2,4 \mathrm{~kg}$ (4 tratamentos $\times 4$ repetições) para cada cultivar. Cada amostra constituiu uma repetição, sendo oito delas destinadas aos tratamentos-testemunha, sem inseticida, sem (4 repetições) e com (4 repetições) adição de insetos $S$. oryzae.

As oito amostras restantes foram destinadas aos tratamentos com o inseticida organofosforado Sumithion 500 CE (concentrado emulsionável, $500 \mathrm{~g}$ de fenitrotion), sem (4 repetições) e com (4 repetições) adição de insetos $S$. oryzae. Cada repetição foi acondicionada em um saco plástico e tratada individualmente.

A dose empregada do produto comercial foi de $20 \mathrm{~mL} \cdot \mathrm{Mg}^{-1}$ de sementes $(0,048 \mathrm{~mL} / 2,4 \mathrm{~kg}$ de sementes). Devido ao pequeno volume que esta dose representa, 4,8 mL do produto comercial foram diluídos em 495,2 mL de água destilada, de modo que foram obtidos $500 \mathrm{~mL}$ de solução. Com o auxílio de uma pipeta, uma alíquota de $5 \mathrm{ml}$ desta solução foi aplicada no interior de cada saco plástico, e agitado vigorosamente, visando à homogeneização do produto sobre as sementes. Em seguida, as sementes foram espalhadas em bandejas plásticas, onde permaneceram durante 24 horas, para secagem da água adicionada.

As sementes tratadas com inseticida e as das testemunhas foram acondicionadas em recipientes de plástico de $17 \times 17 \times 23 \mathrm{~cm}$, tampados com tecido de voile, para permitir o equilíbrio do teor de água das sementes com a umidade relativa do ar e temperatura do ambiente de armazenamento, no Laboratório de Análise de sementes do IAC, localizado em Campinas (SP). Periodicamente, essas sementes foram expurgadas, da forma já descrita, para evitar infestações por insetos indesejados.

Os dados de umidade relativa do ar e de temperaturas máxima, média e mínima, registrados por termohigrógrafo no Centro Experimental de Campinas durante o armazenamento das sementes encontram-se na figura 1 .

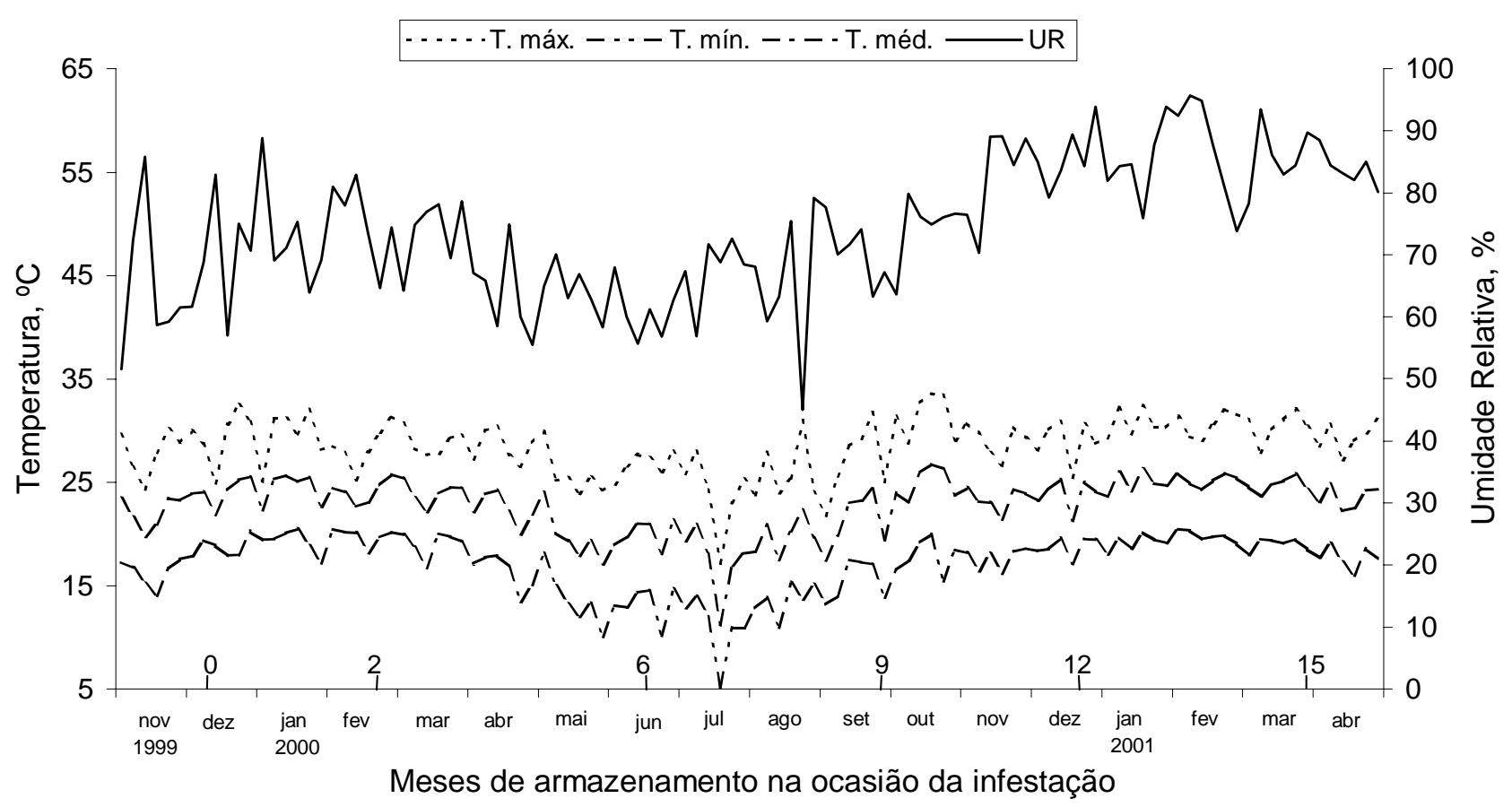

Figura 1. Dados de temperatura mínima, média e máxima e de umidade relativa do ar, observados durante o armazenamento das sementes de trigo dos cultivares IAC-120 e IAC-350, em Campinas (SP). 
Logo após o tratamento das sementes, amostras de $200 \mathrm{~g}$ de cada repetição foram retiradas e colocadas em copos plásticos de $400 \mathrm{~mL}$, para realização das avaliações iniciais da qualidade das sementes (dezembro de 1999). Posteriormente, em intervalos trimestrais, até serem completados 15 meses de armazenamento e 18 meses após a colheita (fevereiro, junho, setembro e dezembro de 2000 e março de 2001), amostras de $200 \mathrm{~g}$ de cada repetição foram acondicionadas em copos plásticos de $400 \mathrm{~mL}$, com tampas.

Foram colocados 20 insetos adultos de $S$. oryzae às repetições pertinentes, de forma que os tratamentos foram assim dispostos: 1) Sementes sem inseticida e sem insetos (Testemunha); 2) Sementes sem inseticida e com insetos; 3) Sementes com inseticida; 4) Sementes com inseticida e insetos.

Os copos foram tampados e colocados em uma câmara regulada a $25^{\circ} \mathrm{C}$ e $60 \%$ de umidade relativa do ar. Após 7 dias, essas amostras foram peneiradas para avaliação da sobrevivência desses insetos. Registrou-se o número de insetos adultos vivos e mortos. Em seguida, esses insetos foram eliminados. Aos 51 dias após a infestação, as sementes foram peneiradas novamente para a contagem da progênie, que também foi eliminada. As sementes de cada repetição foram expurgadas da forma descrita, para impedir a continuidade do desenvolvimento dos ovos, larvas e pupas, que ainda estivessem no seu interior.

Na época inicial (dezembro de 1999) e em cada uma das cinco épocas seguintes, após os insetos terem sido retirados (abril, agosto e novembro de 2000 e fevereiro e maio de 2001), as sementes foram avaliadas, empregando-se os seguintes testes:

Teor de água das sementes: com uma amostra de $5 \mathrm{~g}$ de cada repetição, pelo método da estufa a $105{ }^{\circ} \mathrm{C}$, durante 24 horas ( BRASIL, 1992 ).

Sementes infestadas: com uma amostra de 50 sementes por repetição, de acordo com as prescrições das Regras Para Análise de Sementes (BRASIL , 1992 ).

Germinação: com uma amostra de 50 sementes por repetição, em rolos de papel-toalha Germitest, à temperatura constante de $20^{\circ} \mathrm{C}$. A avaliação das plântulas normais foi realizada aos 7 dias, de acordo com as prescrições das Regras para Análise de Sementes (BRASIL, 1992).

O delineamento experimental empregado foi o inteiramente casualizado em esquema de parcelas subdivididas no tempo; as parcelas foram constituídas por 6 épocas trimestrais de avaliação e as subparcelas, de quatro tratamentos (inseticida e insetos), com quatro repetições.
Os dados obtidos para cada cultivar foram submetidos à análise de variância, empregando-se o Programa de Análise Estatística - SANEST (ZONTA e MACHADO, 1984). As médias foram comparadas pelo teste de Tukey ao nível de 5\%.

\section{RESULTADOS E DISCUSSÃO}

\subsection{Eficiência do Fenitrotion no controle de S. ryzae em sementes de trigo}

Considerando-se as duas cultivares estudadas, nota-se que a porcentagem de sobrevivência dos insetos adultos de $S$. oryzae nas sementes da testemunha foi de $95 \%$ a $100 \%$, em todas as épocas (Quadro 1).

$\mathrm{O}$ inseticida fenitrotion não promoveu controle satisfatório desses insetos, de modo que, apenas nas sementes de 'IAC-350' e quando os insetos foram colocados nas sementes até seis meses após o tratamento, a porcentagem de sobrevivência mostrouse significativamente menor do que na testemunha (Quadro 1), mas com valores superiores a 65\%.

Desta forma, os resultados obtidos na presente pesquisa foram conflitantes com as observações de KAMEL e FAM (1973), que obtiveram controle de S. oryzae durante seis meses. Também não confirmaram as informações obtidas por PAWAR e YADAv (1985), que controlaram S. oryzae com o inseticida fenitrotion durante quatro meses, e ainda contrastaram com os resultados obtidos por PINTO et al. (1997); nesse caso, o fenitrotion com a mesma formulação e dose menor (15 mL. $\mathrm{Mg}^{-1}$ de sementes) do que a que foi empregada na presente pesquisa (20 mL. $\mathrm{Mg}^{-1}$ de sementes), se mostrou eficiente no controle $S$. oryzae, por até 60 dias após a aplicação, em arroz acondicionado em sacos de ráfia e armazenado à temperatura de $25^{\circ} \mathrm{C}$.

Esse inseticida também não impediu a procriação (Quadro 2). As progênies resultantes apresentaram valores numéricos inferiores aos daquelas desenvolvidas na testemunha em todas as épocas; as diferenças, porém, foram significativas apenas até seis meses após o tratamento para as duas cultivares e no décimo quinto mês para a cultivar IAC-120.

Pode-se observar ainda que as progênies obtidas, tanto nas sementes da testemunha quanto nas tratadas com inseticida, foram significativamente maiores aos seis meses de armazenamento e apresentaram valores numéricos menores aos nove meses.

Embora todas as infestações tenham sido efetuadas em câmara à temperatura de $25^{\circ} \mathrm{C}$ e umidade relativa do ar de $60 \%$, empregando-se insetos também criados nessas condições, de acordo 
com Michael et al. (2000), as populações de insetos podem exibir um fenômeno fisiológico, refletindo um comportamento característico das populações selvagens, de variação da população em virtude da estação do ano.

Esse fato pode explicar as menores progênies obtidas quando a infestação foi realizada aos nove meses de armazenamento (meados de setembro de 2000), coincidindo com o fim do período mais seco e de temperaturas mais amenas do ano (Figura 1). Normalmente, na natureza, não há insetos em número suficiente para infestar significativamente sementes de trigo armazenadas nessa época. Segundo os estudos realizados por SEDLACKe et al., (1991); FRANK et al. (1992) e GILbERT e RAWORTH (1996), as condições de temperatura e umidade relativa características da época, não são favoráveis ao desenvolvimento desses insetos.

Quando as sementes foram infestadas no fim do outono (início de junho), aos seis meses de armazenamento, verificaram-se as maiores progênies, de forma não esperada, pois a procriação coincidiu com o período mais seco e de temperaturas mais baixas de 2000 (Figura 1) no ambiente externo à câmara.

A cultivar IAC-350 se caracteriza por apresentar sementes bem mais duras do que as da IAC-120; embora ambas não tenham sido comparadas estatisticamente, verifica-se que o comportamento das sementes, dos insetos e a eficácia do inseticida foram, de modo geral semelhantes para as duas cultivares estudadas. Por outro lado, a obtenção de progênies com valor numérico visivelmente menor, nas sementes de 'IAC-350' tratadas ou não com inseticida (Quadro 2), na época que favoreceu o desenvolvimento da população de insetos (seis meses de armazenamento), pode ter ocorrido devido à maior dureza das sementes dessa cultivar em comparação às sementes da 'IAC-120'.

McGaUghey et al. (1990) também observaram que a dureza do grão pode influenciar fortemente a habilidade de $S$. oryzae em se reproduzir no trigo armazenado. Por isso, sementes de cultivares diferentes apresentam diversos níveis de resistência a insetos de armazenamento (Sing e Mathew, 1973, McGaughey et al. 1990, Cortez-Rocha et al. 1993).

No quadro 3, encontram-se as médias do teor de água das sementes obtidas na época inicial de avaliação e nas épocas seguintes, imediatamente após os insetos terem sido retirados das sementes, que haviam permanecido por 60 dias à temperatura de $25^{\circ} \mathrm{C}$ e umidade relativa de $60 \%$. Observa-se que as sementes da testemunha das duas cultivares, infestadas por S. oryzae, apresentaram valores numéricos de teores de água superiores aos verificados nos demais tratamentos em todas as épocas. Porém, apenas quando as sementes de ambas as cultivares foram infestadas no sexto mês, e as de 'IAC-350', no décimo quinto mês, apresentaram teores de água significativamente superiores ao das sementes dos tratamentos sem insetos, coincidindo com as maiores progênies obtidas no experimento.

Apesar de insetos adultos também terem sobrevivido (Quadro 1) e gerado uma progênie considerável (Quadro 2) nas sementes tratadas com fenitrotion, apenas as da cultivar IAC-120, infestadas no sexto mês, apresentaram maiores teores de água do que aquelas que não foram infestadas, tratadas ou não, coincidindo com a maior progênie obtida para este tratamento.

De fato, as larvas de S. oryzae produzem muito calor metabólico e umidade durante o desenvolvimento, podendo então modificar o microclima local (PACHeco e PAULA, 1995). Por esse motivo, as progênies observadas quando a infestação foi realizada no sexto mês, sobretudo nas sementes da testemunha, e também nas tratadas com inseticida, resultaram em sementes com teores de água tão elevados, em comparação aos tratamentos sem insetos. À medida que os teores de água das sementes aumentam, atingindo níveis entre $14 \%$ e $16 \%$, a fecundidade desses insetos torna-se ainda maior (EvANs, 1982) aumentando ainda mais o tamanho da progênie e conseqüentemente o teor de água, como se verificou nas sementes desses tratamentos.

A ausência de sementes danificadas na época inicial de avaliação demonstra que as sementes empregadas não haviam sido infestadas por insetos anteriormente ao início do experimento (Quadro 4).

O padrão mais recente de infestação por insetos, estabelecido para a comercialização das sementes da safra 2000/2001 e homologado pela Comissão Estadual de Sementes e Mudas do Estado de São Paulo (São Paulo, 2000/2001), é de 5\% para milho, milho-pipoca e sorgo. Embora não haja referência ao padrão de infestação de sementes de trigo, as pragas que atacam as sementes dessas espécies são as mesmas, e o prejuízo causado às sementes de trigo por S. oryzae é ainda maior, devido à preferência desses insetos por sementes dessa cultura (SHARMA e CHAHAL, 1977).

De acordo com esse padrão, as sementes infestadas, em níveis prejudiciais à integridade de um lote de sementes, foram constatadas principalmente na testemunha sem tratamento e com adição de insetos em quase todas as épocas, coincidindo com as maiores progênies (Quadro 2); também foram verificadas no tratamento com inseticida, de forma que as sementes do cultivar IAC-120, deveriam ser recusadas para comercialização quando infestadas aos seis meses após a aplicação de inseticida e as do IAC350 desde os dois meses (Quadro 4). 
Quadro 1. Valores médios de porcentagem de sobrevivência de adultos de S. oryzae, após 7 dias da infestação em sementes de trigo, em função de tratamentos e de meses de armazenamento, em Campinas (SP)

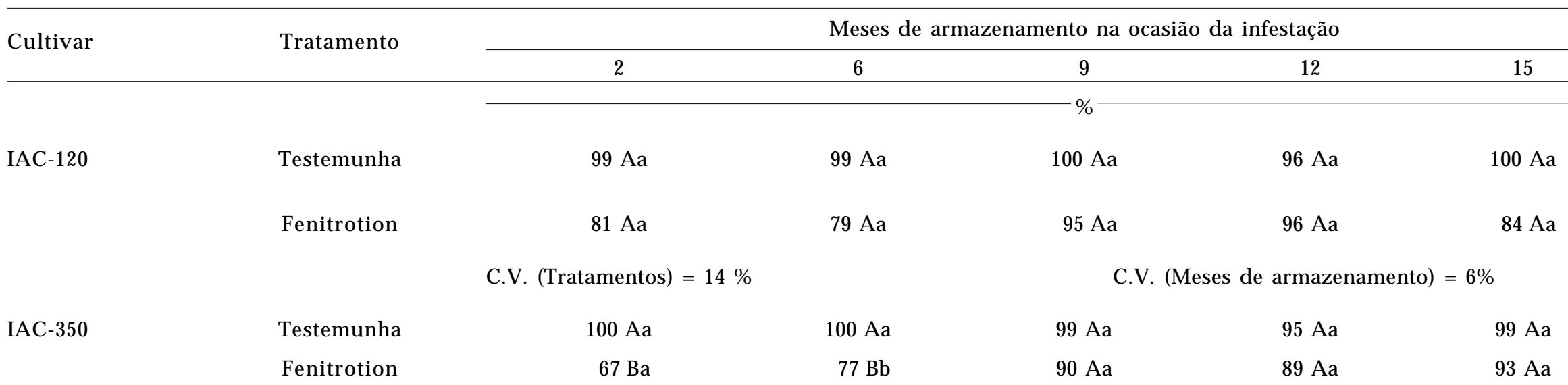

C.V. (Tratamentos) $=21 \%$

C.V. (Meses de armazenamento) $=12 \%$

Médias seguidas pela mesma letra maiúscula na coluna e minúscula na linha não diferiram entre si a 5\%, pelo teste de Tukey. 
Quadro 2. Valores médios do número de insetos da progênie de S. oryzae, desenvolvida em sementes de trigo, em função de tratamentos e de meses de armazenamento, em Campinas (SP)

\begin{tabular}{|c|c|c|c|c|c|c|}
\hline \multirow{2}{*}{ Cultivar } & \multirow{2}{*}{ Tratamento } & \multicolumn{5}{|c|}{ Meses de armazenamento na ocasião da infestação } \\
\hline & & 2 & 6 & 9 & 12 & 15 \\
\hline \multirow[t]{3}{*}{ IAC- 120} & Fenitrotion & $291 \mathrm{Ab}$ & $2453 \mathrm{Aa}$ & $100 \mathrm{Ac}$ & $235 \mathrm{Abc}$ & $224 \mathrm{Abc}$ \\
\hline & Testemunha & $78 \mathrm{Bb}$ & $1057 \mathrm{Ba}$ & $37 \mathrm{Ab}$ & $81 \mathrm{Ab}$ & $48 \mathrm{Bb}$ \\
\hline & \multicolumn{3}{|c|}{ C.V. $($ Tratamentos $)=31 \%$} & \multicolumn{3}{|c|}{ C.V. $($ Meses de armazenamento $)=18 \%$} \\
\hline \multirow[t]{3}{*}{ IAC-350 } & Testemunha & $384 \mathrm{Ab}$ & $1462 \mathrm{Aa}$ & $79 \mathrm{Ac}$ & $161 \mathrm{Ac}$ & $254 \mathrm{Abc}$ \\
\hline & Fenitrotion & $84 \mathrm{Bb}$ & $363 \mathrm{Ba}$ & $36 \mathrm{Ab}$ & $40 \mathrm{Ab}$ & $73 \mathrm{Ab}$ \\
\hline & & tamentos & & \multicolumn{3}{|c|}{ C.V. $($ Meses de armazenamento $)=24 \%$} \\
\hline
\end{tabular}

Médias seguidas pela mesma letra maiúscula na coluna e minúscula na linha não diferiram entre si a 5\%, pelo teste de Tukey. 
Quadro 3. Valores médios do teor de água das sementes trigo, após os insetos terem sido retirados, em função de tratamentos e de meses de armazenamento, em Campinas (SP)

\begin{tabular}{|c|c|c|c|c|c|c|c|}
\hline \multirow{2}{*}{ Cultivar } & \multirow{2}{*}{ Tratamento } & \multicolumn{6}{|c|}{ Meses de armazenamento na ocasião da infestação } \\
\hline & & 0 & 2 & 6 & 9 & 12 & 15 \\
\hline \multirow{4}{*}{ IAC-120 } & Testemunha & $11,9 \mathrm{Aa}$ & $12,3 \mathrm{Aa}$ & $11,7 \mathrm{Ca}$ & $12,5 \mathrm{Aa}$ & $13,6 \mathrm{Aa}$ & $12,9 \mathrm{Aa}$ \\
\hline & Testemunha + insetos & $12,8 \mathrm{Ab}$ & $13,5 \mathrm{Ab}$ & $21,0 \mathrm{Aa}$ & $13,6 \mathrm{Ab}$ & $14,1 \mathrm{Ab}$ & $13,3 \mathrm{Ab}$ \\
\hline & Fenitrotion & $12,1 \mathrm{Aa}$ & $12,5 \mathrm{Aa}$ & $11,7 \mathrm{Ca}$ & $12,6 \mathrm{Aa}$ & $13,3 \mathrm{Aa}$ & $12,4 \mathrm{Aa}$ \\
\hline & Fenitrotion + insetos & $11,9 \mathrm{Ab}$ & $12,3 \mathrm{Aab}$ & $15,5 \mathrm{BCa}$ & $12,8 \mathrm{Aab}$ & $13,0 \mathrm{Aa}$ & $12,9 \mathrm{Aab}$ \\
\hline & \multicolumn{3}{|c|}{ C.V. $($ Tratamentos $)=3 \%$} & & \multicolumn{3}{|c|}{ C.V. (Meses de armazenamento) $=7 \%$} \\
\hline & Testemunha & $12,9 \mathrm{Aa}$ & $12,7 \mathrm{Aa}$ & $11,7 \mathrm{Ba}$ & $12,6 \mathrm{Aa}$ & $13,9 \mathrm{Aa}$ & $13,6 \mathrm{ABa}$ \\
\hline \multirow[t]{3}{*}{ IAC-350 } & Testemunha + insetos & $12,6 \mathrm{Ab}$ & $13,8 \mathrm{Ab}$ & $19,7 \mathrm{Aa}$ & $13,6 \mathrm{Ab}$ & $14,5 \mathrm{Ab}$ & $16,1 \mathrm{Aab}$ \\
\hline & Fenitrotion & $11,9 \mathrm{Aa}$ & $12,7 \mathrm{Aa}$ & $14,5 \mathrm{Ba}$ & $12,6 \mathrm{Aa}$ & $13,5 \mathrm{Aa}$ & $12,4 \mathrm{Ba}$ \\
\hline & Fenitrotion + insetos & $12,4 \mathrm{Aa}$ & $12,7 \mathrm{Aa}$ & $13,0 \mathrm{Ba}$ & $12,8 \mathrm{Aa}$ & $13,0 \mathrm{Aa}$ & $12,3 \mathrm{Ba}$ \\
\hline
\end{tabular}

Médias seguidas pela mesma letra maiúscula na coluna e minúscula na linha não diferiram entre si a 5\%, pelo teste de Tukey. 
Quadro 4. Valores médios de sementes de trigo, infestadas por insetos, em função de tratamentos e de meses de armazenamento, em Campinas (SP)

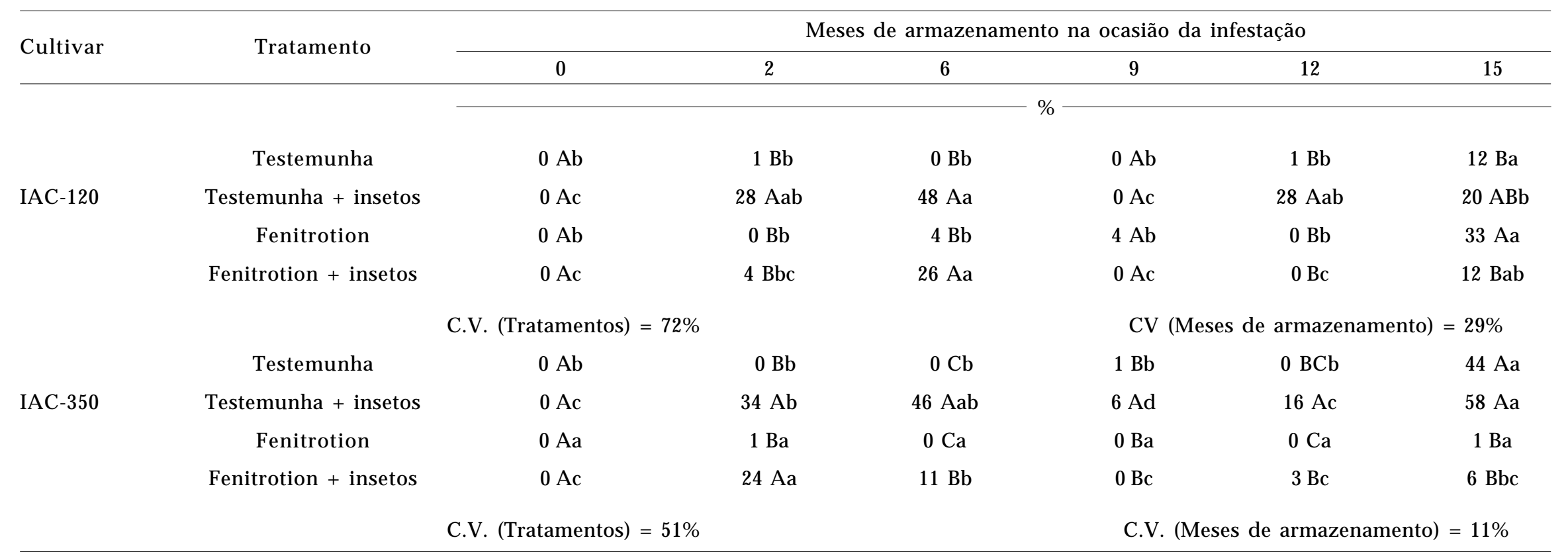

Médias seguidas pela mesma letra maiúscula na coluna e minúscula na linha não diferiram entre si a 5\%, pelo teste de Tukey. 
Quando a infestação foi realizada no nono mês, a porcentagem de sementes infestadas foi baixa, mesmo na testemunha, refletindo as menores progênies obtidas nessa época.

Observou-se também, que até os doze meses de armazenamento houve uma pequena porcentagem de sementes infestadas ( 0 a $4 \%$ ) nos tratamentos sem insetos, apesar dos expurgos freqüentes e do acondicionamento em recipientes cobertos com tecido de voile. Aos quinze meses essa infestação indesejada aumentou também nestes tratamentos, com exceção das sementes do 'IAC-350' tratadas com o inseticida. Este fato demonstra que a vedação dos recipientes não foi totalmente eficiente.

A umidade relativa do ar na fase final do armazenamento das sementes (Figura 1) foi a mais elevada de todo o período experimental, oscilando entre $75 \%$ e $85 \%$ e a temperatura média em torno de $25{ }^{\circ} \mathrm{C}$. Estas condições, ótimas para o desenvolvimento e a reprodução dos insetos de armazenamento, consideradas por Hangstrum e Throne (1989) e Sedlacke et al. (1991) como os principais fatores que influenciam as tendências populacionais quanto aos efeitos sobre o período de desenvolvimento e a produção de ovos dos insetos de grãos armazenados, também devem ter contribuído para a ocorrência da infestação espontânea verificada nesta época, durante o armazenamento das sementes no laboratório e anteriormente à realização da última infestação.

Vale ressaltar que, apesar das porcentagens relativamente elevadas de sementes infestadas aos dois meses (Quadro 4) nos tratamentos com insetos, o potencial de germinação se manteve elevado (Quadro 5). Nessa época, as sementes das duas cultivares eram mais novas e provavelmente mais vigorosas e por isso resistiram melhor aos danos provocados pelos insetos do que nas épocas posteriores. Além disso, a atividade dos insetos nessa época não foi suficiente para elevar consideravelmente o teor de água das sementes, fator que aceleraria o metabolismo e, conseqüentemente a deterioração das sementes (Quadro 3).

Apenas por ocasião da infestação realizada aos seis meses de armazenamento, os valores de germinação (Quadro 5) passaram a refletir os níveis de danos causados pelos insetos, (Quadro 4) tanto às sementes da testemunha quanto às tratadas com o inseticida. Nesse caso, a queda na germinação resultou não apenas da perda da integridade física das sementes, resultante da alimentação e multiplicação dos insetos, mas também da aceleração da deterioração, causada pelos elevados teores de água das sementes, resultantes da atividade dos insetos (Quadro 3). Essa foi, portanto, a época que melhor evidenciou os efeitos da infestação das sementes de trigo sobre o teor de água e a viabilidade das sementes.

Foi nessa época também que os valores de germinação passaram a revelar a ineficácia do inseticida quanto à proteção às sementes, contra o inseto $S$. oryzae, que já havia sido evidenciada pelo nível de sementes danificadas, quando a infestação foi realizada aos dois meses (Quadros 1, 2 e 4). Embora o inseticida fenitrotion aparentemente tenha oferecido uma relativa proteção às sementes da cultivar IAC-350, refletida na obtenção de porcentagem de germinação superior a $80 \%$ quando a infestação de sementes foi realizada aos seis meses de armazenamento, estas sementes também deveriam ter sido recusadas por ultrapassarem o padrão de $5 \%$ de sementes infestadas por insetos (Quadro 4), estabelecidos para o milho, (SÃo PaUlo, 2000/2001).

\subsection{Viabilidade das sementes de trigo durante o armazenamento}

Analisando-se o quadro 5, nota-se que o produto fenitrotion aplicado às sementes não produziu nenhum efeito fitotóxico, como se pôde constatar pelos resultados elevados de germinação, acima de $95 \%$, e semelhantes ao da testemunha (sem e com insetos), observados na época inicial (Quadro 5), confirmando as informações obtidas por KAMEL e FAM (1973) de que os valores de germinação não são afetados por esse produto. Nas épocas seguintes, de modo geral, a germinação das sementes não infestadas, tratadas ou não com inseticida também foi semelhante, demonstrando que o inseticida não interferiu no potencial de conservação das sementes.

Desta forma, considerando-se apenas os tratamentos sem infestação por insetos, verifica-se que a porcentagem de germinação das sementes da testemunha do cultivar IAC-120 se manteve praticamente inalterada durante 11 meses após a data do tratamento e 14 meses após a colheita, quando a infestação foi realizada aos nove meses após o tratamento. As sementes da mesma cultivar tratadas com fenitrotion também mantiveram níveis elevados de viabilidade pelo mesmo período, apesar de terem apresentado um resultado inferior de germinação, quando a infestação foi realizada aos seis meses de armazenamento.

As sementes da cultivar IAC-350 também apresentaram qualidade fisiológica excelente, de modo que os valores de germinação tanto da testemunha quanto das sementes tratadas com fenotrotion, na ausência de insetos, mantiveram-se acima do padrão estabelecido em São PaUlo (2000/2001), durante 15 meses após o tratamento e 17 meses após a colheita, quando a infestação foi realizada aos 12 meses de armazenamento em condições de ambiente. 
Quadro 5. Valores médios de plântulas normais obtidos no teste de germinação de sementes de trigo, em função de tratamentos e de meses de armazenamento, em Campinas (SP)

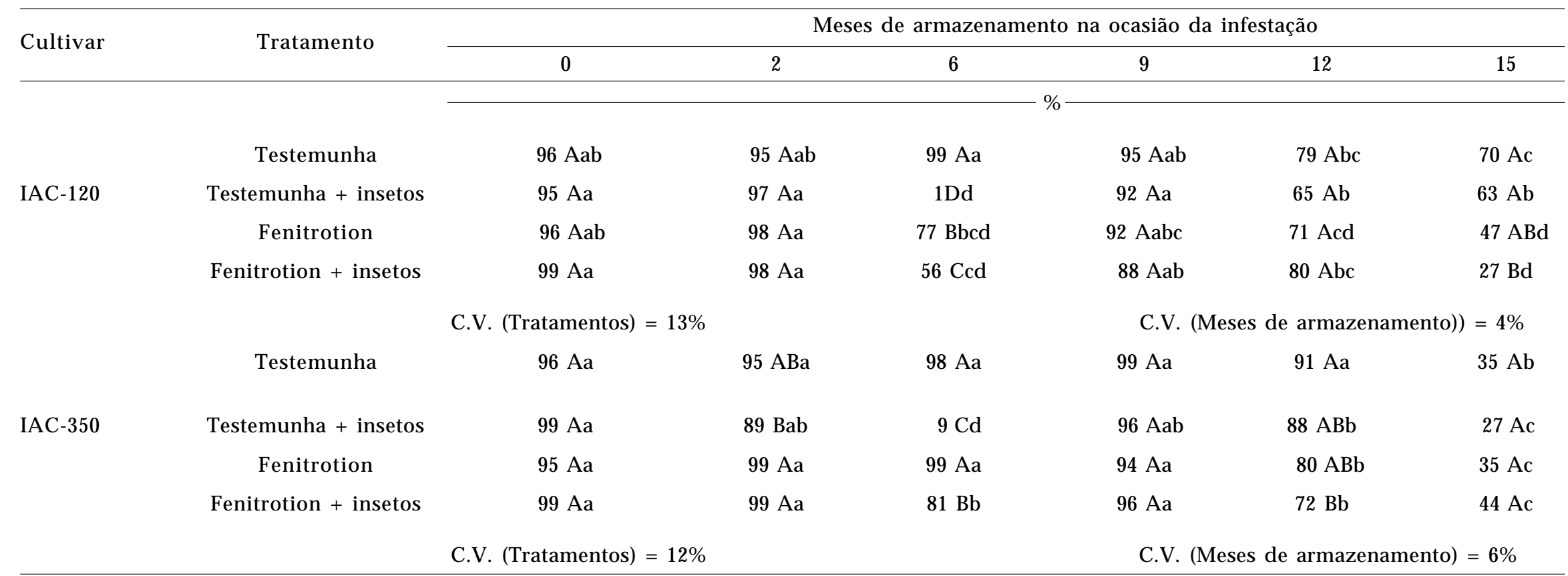

Médias seguidas pela mesma letra maiúscula na coluna e minúscula na linha não diferiram entre si a 5\%, pelo teste de Tukey. 
A queda significativa na germinação das sementes das duas cultivares evidenciou-se a partir da quinta época de testes, em todos os tratamentos, com exceção da testemunha sem insetos da cultivar IAC350; porém, a viabilidade foi reduzida mais drasticamente na última época, inclusive nos tratamentos sem insetos, provavelmente, devido ao elevado nível de sementes infestadas espontaneamente (Quadro 4) e à deterioração inerente à própria semente, submetida aos períodos mais quentes e úmidos do armazenamento, que coincidiram com as duas últimas épocas de testes, de fevereiro a abril de 2001 (Figura 1). Nessas condições como é amplamente conhecido, o metabolismo é acelerado e as sementes, colhidas há mais de doze meses e armazenadas em condições ambientes, se deterioram com facilidade.

\section{CONCLUSÕES}

1. O inseticida fenitrotion, na dose recomendada pelo fabricante, não oferece proteção suficiente às sementes de trigo contra a infestação de $S$. oryzae, mesmo durante o armazenamento por períodos curtos, de dois meses.

2.Tratadas ou não com o inseticida e na ausência de $S$. oryzae, sementes de trigo com elevado potencial de germinação inicial podem mantê-lo inalterado por períodos de 14 a 17 meses após a colheita, quando armazenadas em condições ambientes, em regiões com clima semelhante ao de Campinas.

\section{AGRADECIMENTOS}

Os autores agradecem aos técnicos de apoio à pesquisa Denise Sayuri Isa, Ivonete Alves dos Santos e Cássio José de Carvalho Miranda pelo auxílio nas análises realizadas no Laboratório de Análise de Sementes do IAC.

\section{REFERÊNCIAS BIBLIOGRÁFICAS}

BRASIL. Ministério da Agricultura. Regras para Análise de Sementes. Brasília, SNDA/DNPV/CLAV, 1992. 365p.

CORTEZ-ROCHA, M.O.; WONG-CORRAL, F.J.; BORBOAFLORES, R.I; SANCHES-MARTINEZ; CINCO-MOROYOQUI, F.J. A study on the susceptibility of wheat varieties to Rhyzopertha dominica. Entomology, F. Southwest, v.18, p.287-291, 1993.

EVANS, D.E. The influence of temperature and grain moisture content on the intrinsic rate of increase of Sitophilus oryzae (L.) (Coleoptera: Curculionidae). Journal of Stored Products Research, Canberra, v.18, n.2, p.55-66, 1982.
GILBERT, N.; RAWORTH, D.A. Insects and temperature-a general theory. The Canadian Entomologist, Ottawa, v.128, p.113, 1996.

FRANK, H. A.; THRONE, J. E.; SIMONAITIS, R. A. Degradation and biological efficacy of chlorpyrifos- metthyl on wheat stored at five temperatures and three moisture contents, Journal of Economic Entomology, Lanham, v.85, n.5, p.1994-2002, 1992.

HAGSTRUM, D.W.; THRONE, J.E. Predictability of stored wheat insect population trends from live history traits. Environmental Entomology, Lanham, v.18, n.4, p.660-664, 1989.

HAREIN, P.K. Chemical control alternatives for stored grain insects. Stored of Cereal Grains and their Products, Saint Paul, p.319-362, 1982.

KAMEL, A.H.; FAM, E.Z. Evaluation of two organophosphorous compounds against certain insects infesting stored grains, Plant Protection Research, Cairo, v.51, n.1, p.21-28, 1973.

McGAUGHEY, W.H.; SPEIRS, R.D.; MARTIN, C.R. Susceptibility of classes of wheat grown in the United States to stored-grain insects. Journal of Economic Entomology, Baltimore, v.83, p.1122-1127, 1990.

MICHAEL, D.T.; CUPERUS, G.W.; PHILLIPIS, T.W. Susceptibility of eight U.S. wheat cultivars to infestation by Rhyzopertha dominica (Coleoptera: Bostrichidae). Environmental Entomology, Lanham, v.29, n.2, p.250-255, 2000.

PAWAR, C.S.; YADAV, T.D. Residues of baythion and fenitrothion on wheat and green gram, Journal of Entomology, New Delhi, v.47, n. 1, p.37-44, 1985.

PACHECO, I.A.;PAULA, D.C. Insetos de grãos armazenados: Identificação e Biologia. Campinas: Fundação Cargill, 1995. 228p.

PINTO, V.R.; FURIATTI, R.S.; PEREIRA, P.R.V.S.; LAZZARI, F.A. Avaliação de inseticidas no controle de Sitophilus oryzae (L.) (Coleoptera: Curculionidae), e Rhyzopertha dominica (Fab.) (Coleoptera: Bostrichide) em arroz armazenado. Anais da Sociedade de Entomologia, Piracicaba, v.26, n.2, p.285-290, 1997.

PUZZI, D. Abastecimento e armazenagem de grãos. 2.ed. Campinas: Instituto Campineiro de Ensino Agrícola, 1986. 605p.

SÃO PAULO. Comissão Estadual de Sementes e Mudas (CESMSP). Padrões de sementes de grandes culturas. São Paulo: CESMSP, 2000/2001. n.p.

SEDLACKE, J.D.; BARNEY, R.J.; PRICE, B.D.; SIDDIQUI, M. Effect of several managent tatics on adult mortality and progeny production of Sitophilus zeamais (Coleoptera: Curculionidae ) on stored corn in the laboratory. Journal of Economic Entomology, Baltimore, v.84, p.100-105, 1991.

SHARMA, S.S.; CHAHAL, B.S. Oviposition response of Sitophilus oryzae (L.) (Coleoptera: curculionidae) on different types of food grains. Bulletin of Grain Technology, Ludhiana, v.15, n.2, p.111-117, 1977.

SING, N.B; MATHEW, G. Comparative resistance of different wheat varieties (to rice weevil Sitophilus oryzae L.) during storage. Journal of Agriculture Science, v.7, p.86-89, 1973. 
SING, N.B.; SINHA, R.N.; WALLACE, A.H. Changes in $\mathrm{O}_{2}$, $\mathrm{CO}_{2}$ and microflora of stored wheat induced by weevils. Environmental Entomology, Lanham, v.6, p.111-117, 1975.

SINHA, R.N.; DEMIANYK, C.J.; McKENZIE, R.I.H. Vulnerability of common wheat cultivars to major storedproduct beetles. Canadian Journal of Plant Science, Ottawa, v.68, p.337-343, 1988.
SNELSON, J.T. Grain Protectants. Canberra: ACIAR, 1987. p.448. (Monograph, n.3).

ZONTA, E.P.; MACHADO, A.A. Sistema de análise estatística para microcomputadores: SANEST. Pelotas: UFPel, 1984. 